\title{
Quality assurance in Latin America: current situation and future challenges
}

\author{
Maria Jose Lemaitre*
}

doi: http://dx.doi.org/10.18543/tjhe-5(1)-2017pp21-40

\begin{abstract}
Quality assurance processes have developed in Latin America since the beginning of the 1990s, trying to deal with the changes in higher education. This article is organized from two main perspectives: the first is mostly descriptive, and it focuses first on a brief outline of structural changes, that impact on the features of higher education in the region; the response from Latin America, in terms of national systems and subregional and regional arrangements; and then on the perceived effects of the implementation of quality assurance mechanisms on higher education institutions. Based on that information, the second part has a prospective approach: it identifies some of the main challenges, that have to do with the need not to do 'more of the same' but rather, to develop a second generation of quality assurance processes, and makes suggestions about possible actions for policy makers, higher education institutions and quality assurance agencies.
\end{abstract}

Keywords: higher education; quality; quality assurance; quality management; policy making.

\section{The context for quality assurance in Latin America}

Changes in higher education are never independent of the national characteristics and of the structural transformations of the social systems where higher education operates. It is necessary, therefore, to place higher education within the specific Latin American context.

Latin America is characterized by significant differences among countries (such as population size, where Brazil has almost seventy times more people than Panama, or per capita income, where Argentina has seven times the income of Nicaragua), but at the same time, by some

* María José Lemaitre (mjlemaitre@ cinda.cl), a sociologist with graduate studies in education, is currently the Executive Director of CINDA, a network of universities in Latin America and Europe.

More information about the authors is available at the end of this article (after the bibliography list). 
common features. Probably one of the more visible commonalities is language. With the exception of Brazil, all countries speak Spanish, and even in that case, basic understanding is not an issue. On the dark side, Latin American countries are among the most unequal countries in the world, which can be seen in the distribution of income (most countries show a Gini coefficient over 0.40 , and some, even over 0.50 ) and also in terms of educational results, where high income students are three times more likely to graduate from secondary education than their poorer counterparts. ${ }^{1}$ Two other features are important from the point of view of higher education. The first refers to demographic changes, which show a clear increase of the adult population, and a decrease of the preschool and school cohorts. As a result, there is not only an increased demand for tertiary education, but it is also becoming more diversified. Secondly, social stratification in Latin America shows a strong increase of middle strata, as a result of the sustained economic growth most of the countries experienced between the mid-eighties to the end of the nineties. At the same time, many of this new arrivals to the middle class associate their mobility, and the possibility of maintaining that status, to access to education. The likelihood of overcoming the poverty threshold increases significantly with twelve years of schooling; in the case of Chile, thirteen or fourteen years of study (two more than secondary level) enable individuals to earn four times the income associated with the poverty level. Access to postsecondary education, therefore, has become a clear necessity for the middle classes. ${ }^{2}$

This relates to some studies that show that educational expectations have two different sources: one, more visible, is highly instrumental. As mentioned before, access to higher education is the threshold to improved occupational opportunities, and to effective social channels to mobility; the second is more symbolic, and has to do with educational goals, that is, vocational definitions and access to a different value system. This explains why, for a significant percentage of students, it is important to have the chance to 'live a university experience' even when it does not lead to a degree. ${ }^{3}$ From this perspective, it is relevant to take into consideration the symbolic component of higher

1 Jose Joaquin Brunner and Daniel Miranda, Educación Superior en Iberoamérica (Santiago: CINDA, 2016), 111-115.

${ }^{2}$ Raul Atria, Tendencias en la Educación Superior. El contexto del Aseguramiento e la calidad (Santiago de Chile: Centro Interuniversitario de Desarrollo (CINDA) \& Ril Editores, 2010), 28.

${ }^{3}$ Maria Jose Lemaitre and Francisco Durán, Hacia una nueva arquitectura del sistema de educación superior: el régimen de lo público (Santiago: Universidad San Sebastián, 2013), 35. 
education, perceived as a mechanism for social differentiation, for access to a style of living and of values identified with higher social strata and for meritocratic considerations to access better labour opportunities that will lead to social mobility. In this respect, the structure of employment shows that there is an increasing demand for 'soft' skills and competencies, as well as more specialized ones, an aspect still seldom taken into account in the design of study opportunities.

These features, so briefly outlined here, shed some light over the main trends affecting the higher education systems in Latin America. The first, clearly present in all countries, albeit with some differences mainly associated from each country's starting point, is the expansion of enrolment. Both the effect of the new demography in the region, and the need for the middle classes to strengthen their status press strongly over higher education. In fact, in some countries it is now possible not only to speak of mass higher education, but also of universal higher education, which is precisely what happens when higher education becomes indispensable for the middle classes. ${ }^{4}$

In all countries, most people from the higher income quintiles already have access to higher education. This means that the growth in enrolment tends to come from groups which have been traditionally excluded from higher education: students with lower income, different cultural capital, lower qualifications, and poorer secondary education; their interests and needs are probably also very different from those of the more traditional students.

This leads to the second trend; also clear in all Latin American countries: the diversification of higher education. Diversity is usually associated either to differences in quality. However, when higher education needs to accommodate a much wider and heterogeneous population of students, it is necessary to recognize that diversity is the only way to respond in an effective and relevant way to a wide range of demands. In Latin America it is possible to identify multiple dimensions of diversity: types of institutions, of programs offered, of modes of teaching and learning, of prestige, of institutional cultures - and, of course, also of quality. Quality is essential, but diversity requires that these differences are taken into account when defining quality or identifying quality criteria and indicators.

A third trend is that of privatization. There are different approaches in this respect, from the extreme privatization of the Chilean case, to the dominance of the public university in Uruguay. However, almost all countries

${ }^{4}$ QAA and British Council, Cultures of Quality: an International Perspective (2015). 
show a strong increase of the private sector, both in number of institutions and in enrolment.

These trends are not peculiar to Latin America. Countries in the region share them with the rest of the world, including also the other trends identified by the OECD in 2008: a diversification of sources of funding, the prioritization of quality assurance arrangements (which will be analysed further in the next section), new forms of institutional governance and the professionalization of management. But there are two features which are specific to the region.

The first has to do with the meaning of institutional autonomy, and especially, the autonomy of universities with regard to national governments. With very few exceptions, governments in LA do not have any say on the operation of higher education institutions; their role is limited to providing some guidance through incentives and specific funding schemes. Higher education policies are usually determined by the main national university or universities, which tend to cover the public sector, and to ignore the private institutions (which in some cases concentrate at least half the enrolment). This responds to a tradition deeply ingrained in the higher education culture, and prevents higher education systems to operate as such, since most the decisions depend on the specific interests of some stakeholders.

The second is probably a consequence of the first one, and refers to the absence of recognized national higher education 'areas' that cover the set of institutions operating in a given country. As an example, the public - private divide means that each sector responds to different policies or decisions; the division between universities and non-university institutions makes it almost impossible to move among different institutions, or have studies or degrees recognized; the distinction between research universities and teaching universities creates strong barriers and sets standards almost impossible to meet by many institutions. Consequently, it is almost impossible to even think of a Latin American higher education area, in spite of multiple efforts in that direction.

\section{Quality assurance processes in the region}

The trends briefly outlined in the above have contributed to an erosion of the social trust in higher education, mainly because of the diversification of providers and the increasing heterogeneity of the student population. Higher education has become for many stakeholders 'a wide and alien 
world', ${ }^{5}$ characterized by the lack of relevant and understandable information. At the same time, they have placed higher education at the centre of social concerns, and of the public agenda in almost all Latin-American countries. Quality assurance schemes have been seen as an effective response to these concerns, and initiatives in this respect can be organized in three different categories: The establishment of national quality assurance systems; the search for sub regional arrangements; the creation of a regional network.

\section{II.1. National quality assurance systems}

Latin America is one of the regions in the world where quality assurance processes have been established longer, with the exception of the United States. Brazil has reviewed graduate programs for over forty years, and during the nineties, Argentina, Chile, Colombia and Mexico had already set up quality assurance mechanisms. Looking at the region, it is possible to see that "each country developed their own, by analysing what kinds of assessment or accreditation of institutions or programmes was more adequate to its needs and traditions, legal arrangements and academic practices. As a result, there is now a wide variety of national experiences, which are the basis for multiple processes of learning and exchange". ${ }^{6}$

This variety also refers to their level of development. Some are quite consolidated, as is the case in Argentina, Brazil, Chile, Colombia, Costa Rica, Cuba or Mexico. Others - Paraguay, Ecuador, Panama, Peru, El Salvador - although created several years ago, have been revised and are currently having a second chance for effective operation. Other countries have developed special arrangements for specific groups of institutions but have not been able to consolidate national systems.

In general, most systems tend towards a range of quality assurance purposes, including quality control (licensing, initial authorization for institutions or programmes, the evaluation of threshold standards), together with accountability or institutional or programme accreditation, and some initiatives where the main focus is the promotion of continuing improvement. This is carried out by one national agency or by different agencies, both public and private.

${ }^{5}$ El mundo es ancho y ajeno (The world is wide and alien) is the name of a novel by Alcides Arguedas, which depicts the cultural shock between white landowners and the indigenous population in Peru.

${ }^{6}$ CINDA, Educación Superior en Iberoamérica (Santiago: CINDA, 2007), 296. 


\section{II.1.1. Ownership}

Almost all QA processes in Latin America were initiated by governments, but they respond to a wide range of models. Some continue to be a part of the governmental structure, such as CONEAU in Argentina, some of the agencies in Colombia or in Bolivia, CEAACES in Ecuador, INEP in Brazil, or current initiatives in the Dominican Republic. Others are organized as public organizations, independent from the government, but with different degrees of autonomy (CNA and CNED in Chile, ANEAES in Paraguay), and still others belong to the main public university or universities in the country (SINAES in Costa Rica, CEUB in Bolivia). In Chile, Mexico and Argentina the national public agencies recognize private agencies, either belonging to associations of higher education institutions, to professional associations or to private groups, supervised by the national QA organization.

\section{II.1.2. Focus}

Most agencies focus either on programme or institutional accreditation. However, there are some initiatives that measure student learning: Colombia tests graduating students with an exit examination called SABER PRO, and Brazil applies ENADE (or National Test of Student Performance) twice during their period of study. Chile has a national test for graduates of medicine, as a requirement for access to specialization programmes, and for graduates of teacher training programmes. These tests have been strongly criticized, for mistrusting the institutions' capacity to reliably assess learning outcomes, for standardizing the curriculum and for reproducing the type of academic learning that should have been assessed during the formative process. At the same time, there is a clear need for professional certification, something that does not exist in Latin America, where HEI certify both academic and professional competencies.

A different focus is the assessment and recognition of accrediting agencies. Chile and Mexico evaluate and supervise the operation of private agencies, charged with programme accreditation in specific fields, and Argentina authorizes agencies for voluntary institutional assessment.

The following table shows the distribution of countries regarding the focus of their QA processes: 
Table

Distribution of Latin American countries by the focus of QA processes

\begin{tabular}{|l|l|}
\hline \multicolumn{1}{|c|}{ Focus of QA processes } & \multicolumn{1}{c|}{ Countries } \\
\hline $\begin{array}{l}\text { Undergraduate } \\
\text { programmes }\end{array}$ & $\begin{array}{l}\text { Argentina, Brazil, Chile, Colombia, Costa Rica, Cuba, } \\
\text { Mexico, Panama, Paraguay, Peru, Uruguay }\end{array}$ \\
\hline Graduate programmes & Argentina, Brazil, Chile, Cuba, Mexico \\
\hline Institutions & $\begin{array}{l}\text { Argentina, Brazil, Chile, Colombia, Cuba, El Salvador, } \\
\text { Panama }\end{array}$ \\
\hline Students & Brazil, Colombia, Chile \\
\hline QA agencies & Argentina, Chile, Mexico \\
\hline
\end{tabular}

\section{II.2. Sub regional arrangements}

There are two significant sub regional arrangements, both of which have tried to harmonize standards and procedures for quality assurance: that of the countries grouped under MERCOSUR - the common market of the South and the initiatives in Central America.

\section{II.2.1. ARCU-SUR: ${ }^{7}$ an international agreement}

In 1998, the Ministers of Education of Argentina, Brazil, Paraguay and Uruguay (the four member countries of MERCOSUR), plus Bolivia and Chile as observers, signed a Memorandum of Understanding leading to the organization of a regional accreditation mechanism. The main purposes of this initiative were to improve the quality of education in the region, contribute to the recognition of qualifications among countries and to student and professional mobility and, in general, to promote and support regional integration.

After a long period of negotiations and discussion, participating countries agreed on a set of shared quality standards for Medicine, Engineering and Agronomy, and common procedures to be applied by the national accrediting agencies. The arrangement was tested in the six countries, and officially approved by the Ministers of Education in 2008.

7 “Sistema ARCU-SUR - Mercosur. s.f.," ARCU-SUL, last visited August 2017, http:// edu.mercosur.int/arcusur/index.php/es/descripcion/127-sistema-arcu-sur-es. 
ARCU-SUR focuses on nationally recognized undergraduate programmes in selected areas ${ }^{8}$ and its processes are aligned with national legislation. It offers public assurance about the academic and scientific level of programmes, determined through their alignment with ARCUSUR core learning outcomes and quality criteria. Participating countries ${ }^{9}$ have agreed to recognize degrees granted by accredited programmes, albeit only for academic purposes.

The end result has not been too encouraging in terms of mobility or recognition of qualifications. Intraregional mobility is not a priority for Latin American countries (only Argentina and Chile are significant destinations for Latin American students), and this agreement - signed by the Ministers of Education - carried little weight with universities which operate with almost total autonomy from their respective governments. However, the process had a strong impact on the strengthening of national agencies, and the development of harmonized standards in the region - a not negligible effect.

\section{II.2.2. Central America}

The Council for Higher Education in Central America (CSUCA), which groups the public universities in the region, started working on the development of a region wide assessment process for higher education with the support of German cooperation agencies in 1995. This process developed basic standards for university programmes, trained hundreds of academic staff and external reviewers and is currently operating mostly for the public universities in the region. Its main contribution has been the introduction of a continuing concern for quality and its regular assessment, and has been the basis for many further developments in the area of quality assurance.

Following this experience, in 2003 the Central American Council for Accreditation (CCA) was established, with the dual role of assessing quality assurance agencies in the region, and of promoting quality assurance initiatives. It brings together governments, public and private higher education institutions and professional associations, and has had a strong role in the development of assessment practices and capacity building.

In addition, specialized agencies with a regional focus have been established: ACAAI, for Engineering and Architecture; ACESAR for food

${ }^{8}$ ARCU- Sur added Veterinary Medicine, Dentistry, Nursing and Architecture to the three initial programmes.

${ }^{9}$ In addition to the original six countries, Venezuela, Peru, Ecuador and Colombia were also included in ARCU-Sur. 
and agricultural programmes; ACAP, for graduate programmes, and ACAFEM, which is in the process of developing standards for Medical Studies.

\section{II.3. The establishment of a regional network}

In 2003, national quality assurance agencies, representatives from governments involved in higher education and several university associations decided to set up a regional network dedicated to the promotion of quality assurance. This involved eighteen Latin American countries plus Spain, and evolved into the Iberoamerican Network for Quality Assurance in Higher Education (RIACES).

Its main purposes were the following:

- To promote the development of quality assurance agencies and of assessment and accreditation processes in member countries

- To support the development of accreditation mechanisms leading to the recognition of degrees, student, academic staff and professional mobility and to the educational integration of the region

- To involve national and international cooperation organizations in the promotion of quality assurance systems

- To analyse the development of higher education in order to make quality assurance an effective tool for the continuing improvement of higher education institutions

After almost a decade of operation, RIACES has made it possible to develop a regional community for quality assurance, and has contributed to capacity building at different levels: existing and emerging agencies, academic staff within higher education institutions, reviewers and policy makers. It has supported the establishment of new quality assurance mechanisms in several countries, and has worked with national agencies towards the harmonization of standards and procedures for the assessment of undergraduate and graduate programmes.

It also has established strong links with INQAAHE, the global quality assurance network; this association makes it possible to approach quality assurance from a double perspective: that of national and regional priorities and concerns, within a shared cultural context, and the global one, which helps put national and regional work in a much wider context and to work together with other regions of the world in matters of common interest. 


\section{Impact of QA on universities - results from a study}

CINDA ${ }^{10}$ conducted, with the support of the European Union, a study to learn about the perceived effect of quality assurance on higher education institutions. ${ }^{11}$ It was conducted in countries with at least five years of experience in the operation of QA processes. ${ }^{12}$ The study selected between six and eight universities in each country, and gathered information from policy makers and institutional stakeholders (academic vicerrectors, directors of planning, heads of department, academic staff, students and graduates), as well as representatives from professional associations. A mixture of surveys, focus groups and interviews were used, and data were analysed both at the country level and across countries, with a focus on institutional management and teaching and learning. Some information was also gathered regarding the role of quality assurance at the system level. The main results are summarized in the following section. ${ }^{13}$

\section{III.1. Higher education systems}

The importance of QA as an effective regulatory mechanism was recognized in all participating countries, although, in a context where governments have a relatively weak regulatory capacity regarding higher education, this operates through the provision of incentives. Institutions report that, although QA can mean a threat to their autonomy, in general these processes have been accepted and universities have adapted their organization better to address them. It was interesting to learn that most respondents valued the definition of quality criteria, thus making explicit the expectations about quality.

${ }^{10}$ CINDA (Center for Interuniversity Development) is a network of prestigious universities in Latin America, Spain and Portugal, established in 1971, which focuses on the contribution of higher education to national and regional development. See www.cinda.cl for further information.

${ }^{11}$ Daniela Torre and Gonzalo Zapata, "Impacto de procesos de aseguramiento de la calidad sobre las instituciones de educación superior: un estudio en siete países", in Aseguramiento de la Calidad en Iberoamérica, ed. Maria Jose Lemaitre and Elisa Zenteno (Santiago: CINDA, 2012), 115-152.

12 Argentina, Chile, Colombia, Costa Rica and Mexico. In addition, the study included two European countries: Spain and Portugal.

${ }_{13}$ Details of the study, as well as national reports can be found (in Spanish) in Lemaitre and Zenteno, Aseguramiento de la Calidad en Iberoamérica (2012). 
Maybe the most consistent result was the development or improvement of national information systems, with a strong emphasis on the role of the government: HEI expect the government to vouch for the reliability and validity of the information, and to regulate the information addressed to students and the general public, in order to control its use for marketing purposes.

\section{III.2. Institutional management}

Institutional leaders emphasized that the need to adapt to quality assurance processes has led higher education institutions to make important changes in their organizational structure. These changes are mostly aligned with an effort to institutionalize the design, control and planning of quality assurance processes, and have resulted in many cases in an increased centralization of decision making processes, which tend to be in the hands of professional managers. Academic staff saw in this an increasing risk of bureaucratization and the emergence of a managerial approach which would reduce the weight of academic considerations in university management.

At the same time, most respondents linked quality assurance processes with an increased recognition of teaching as a key function in universities; in many cases, this has begun to be translated into the development of new evaluation and promotion mechanisms for academic staff, although it is also clear that this is still in its very initial stages.

Respondents at different decision making levels reported that there is a clear improvement of information systems within universities, and that it is increasingly used as the underlying justification for most decisions. In many cases, the assumption was that more information would necessarily translate into better management, but this seems only to be true if there is a clear understanding of the type of information that is truly relevant for decision makers at the different institutional levels. In fact, academic staff complained that gathering and providing the required data was a very heavy load that fell mostly to them, and that, with few exceptions, the processed information did not find their way back for them to improve their work. This suggests that there is a need to identify what information is really needed to improve decision making processes, and the kind of processing and analysis that is necessary for it to be useful to different levels of decision makers.

Finally, most respondents mentioned that quality assurance had triggered changes in the criteria and practices for hiring academic staff; while these were an improvement over previous practices, they mostly focused on formal 
aspects (such as the level of qualifications, in response to the use of quantitative indicators) rather than on more substantive elements, better linked to the actual quality of teaching or research.

\section{III.3. Teaching and learning}

Academic staff reported significant changes in the formulation of expected learning outcomes, curricular design and updating of study plans as a result of participation in quality assurance processes. The increased availability of information on student progress and follow up of graduates - directly related to the demand for effectiveness in quality assurance standards and procedures has contributed to a stronger concern about the relevance of programmes and the need to improve teaching strategies, methodologies and practices.

Internal stakeholders, particularly those directly involved in the teaching process - heads of department, lecturers, students - greatly valued the focus that quality assurance processes place on teaching and learning, but considered that they tend to focus mostly on formal aspects and indicators, without paying attention to more substantive issues, or to have a strongly prescriptive focus, emphasizing certain practices that may not be adequate in specific contexts.

With regard to teaching strategies and practices, academic staff saw a direct influence from quality assurance in basic changes, such as improved reading lists and materials, or updated and better teaching resources. At the same time, they report that the need to review teaching and learning within the context of programme accreditation has contributed to the introduction of innovative practices, such as the use of ICT, competency based teaching, and new assessment methods (even though they recognize that changes in the assessment of learning are still more of an expected outcome than actual practice).

\section{The main challenges for quality assurance}

Maybe one of the main current challenges derives from the success in the implementation of quality assurance processes. These achieved a high degree of legitimacy and made significant progress in the development of a 'culture of quality', that is, in the increasing capacity of institutions to systematically analyse their processes.

But most quality assurance agencies continue carrying out review processes that focus on the same unit or units of analysis, with the same 
criteria, and little consideration of the institution's progress. As a result, both quality assurance agencies and higher education institutions have developed a more formal and bureaucratic approach to self-assessment and external review, which in turn makes them relatively irrelevant exercises from the point of view of institutional improvement.

A second challenge emerges from the social importance linked to accreditation: both governmental policies and the market have come to place a significant value on the accredited status of an institution or programme; therefore, accreditation has become the goal rather than the means to help institutions or programmes to improve.

It has become necessary, therefore, to explore how to move on to a second generation of quality assurance which, taking into account the positive results of the first stage, is able to encourage and push institutions towards continuing improvement.

One way of doing this is through a shift from the usual quality assurance approach based on a set of undifferentiated standards and criteria towards a focus on the systematic review of institutional priorities and purposes.

This would require re-defining quality as the combination of two main factors: internal consistency, and external consistency.

Internal consistency means the capacity of an institution or programme to identify and to analyse its significant environment based on its stated mission, or in other words, on its principles and priorities, in order to select the demands, it is able to take into consideration.

External consistency refers to the capacity of an institution to understand and take into account the needs and demands that emerge from decisions such as the balance of institutional functions, the areas of knowledge to be covered, the disciplinary or professional requirements linked to the programmes it offers, the type of students it will enrol, the needs and demands of the labour market.

Quality, in this approach, is measured on the basis of the capacity of an institution to adjust its resources, processes, products and outcomes to the requirements coming from the selected needs and demands. The main components of quality, in this approach, would be a combination of institutional identity and its effective and relevant operation.

To evaluate the degree in which institutional staff, processes and resources are effectively aligned both to institutional priorities and the needs and demands of their constituents would encourage institutions not just to meet external stipulations, but to plan for an improved response capacity.

This approach is normally associated with academic audit mechanisms, but it can also be effectively used in accreditation processes, where criteria and procedures focus on the institution's responsibility for its continuing 
improvement, and where institutional or programmatic diversity play a significant role in the way in which quality is defined and reviewed.

If quality assurance processes focus on strengthening the institutional capacity for the management of quality - including the installation of effective tools, such as a function of institutional research - they could actively contribute to make institutions responsible for the quality of their actions and results, thus reducing the supervisory approach most quality assurance processes now have.

A third challenge, also linked to the success of quality assurance processes, is the trend - present in many countries - to use these processes essentially as regulatory mechanisms. In a context where one of the features of higher education is its independence from governmental action, the discovery that quality assurance processes are an effective way to steer higher education institutions have turned them into particularly attractive mechanisms for control and regulation. The importance of having in place quality control tools - such as licensing requirements or threshold standards - should not interfere with the need to have in place schemes for accountability or the support of institutional improvement.

Then there is the challenge posed by diversity. As mentioned above, one of the features of the region is its diversity - among and within countries and also among and within higher education systems and institutions. However, most quality assurance schemes use the same criteria for universities and non-university institutions, for public and private providers, for institutions large and small, for those focusing on research and those that are essentially teaching institutions. In a context of growing enrollment, and where the student population is increasingly heterogeneous, it has become necessary to find ways of defining criteria and indicators that are appropriate to the needs of diversity, in the terms already defined by Martin Trow in 1995:

... the existence of distinct forms of post-secondary education, of institutions and groups of institutions within a state or nation that have different and distinctive missions, educate and train for different lives and careers, have different styles of instruction, are organized and funded differently and operate under different laws and relationships to government. ${ }^{14}$

This poses a challenge that goes beyond quality assurance, that is, the need to re-invent higher education. This means wondering whether in this context, is the university the best way to develop and transfer certain types of knowledge?

${ }^{14}$ Martin Trow, "Diversity in higher education in the United States of America" (paper presented at the CVCP Seminar on Diversity in Higher Education. London, 14-15 September, 1995). 
If universities are the most prestigious and attractive institutions and students pay more attention to the type of institution they enroll in than to the degree or the achieved competencies, is it necessary to protect universities from diversification? Or rather, is it preferable to leave aside the traditional concept of university, and accept that its role is currently defined more in terms of social and economic returns? Probably the best answer is that both views are right, but the way in which this question is answered is key for the definition of quality, and by extension, for quality assurance. The problem is that there are questions that nobody is ready to consider, because they may lead to a new paradigm, which is hard to accept. Today, higher education institutions and quality assurance agencies operate in an ambiguous context, where new and diverse institutions uphold the new role for higher education, but at the same time, try to imitate their traditional colleagues. In spite of the rhetoric that insists on the need to focus quality assurance processes on institutional mission and purposes, there is still a strong influence of traditional models through the use of quantitative indicators or regulatory requirements.

Finally, there is a challenge that is linked to the professionalization of quality assurance processes. A set of scoping studies on quality assurance, commissioned by UNESCO in different regions of the world, concluded that ironically, while external quality assurance agencies actively work to generate quality assurance capacities in higher education institutions, they almost completely ignore the need to improve their own capacity to focus on quality and its improvement..$^{15}$ The study coordinated by CINDA on the impact of quality assurance on higher education institutions also came to similar conclusions. While many of the complaints focus on peer reviewers (possibly, because they are the visible face of the agency), these usually refer to flaws in the agencies' norms and procedures. Quality assurance has become a recognized professional field, with clearly established practices and agencies should take into consideration the training of their technical and policy making staff as one of their priority actions.

\section{Possible initiatives for the improvement of quality assurance in the region}

Based on the experience of these twenty something years of experience, it is possible to suggest specific actions for the main stakeholders in the

${ }^{15} \mathrm{UNESCO}$, Summary report of the E-Forum on quality assurance in higher education (Paris: UNESCO, 2015). 
higher education system which would make it easier to update quality assurance practices and to emphasize their role to enhance the quality of higher education offerings.

\section{V.1. Policy makers}

Quality assurance is clearly a policy instrument, and as such, it should develop within a framework of national purposes and priorities, aligned with other policy mechanisms. Some of them are listed below:

- The recognition and appreciation of the diversity of higher education institutions, programmes, teaching modes, and other related aspects in policies on access, funding, regulation and public information.

- The design, development and maintenance of valid and reliable information systems that clearly state the type of information that must be provided by higher education institutions. Information systems should increase the transparency of higher education offerings and take into account the needs of different users, including potential students, their families, employers and the general public.

- Quality assurance is a significant component of public policy. As such, it is frequently required to respond to a variety of purposes only loosely associated with quality; it is necessary to understand its limitations, and link quality assurance with other policy instruments in a consistent and effective manner.

\section{V.2. Higher education institutions}

The main quality assurance networks have insisted that quality is essentially the main responsibility of higher education institutions themselves, and this should be taken into account when designing standards and procedures for external quality assurance. Therefore, institutions, their leaders, academic and administrative staff and students also have a role to play in order to enhance quality and to contribute to the effectiveness of quality assurance. The main priorities are:

- Promoting the institutional capacity for the management of quality: the definition and use of information systems to support decision making; setting up an institutional research function, able to gather, process and 
analyse relevant information for the different levels of the institution; links between quality assurance processes and institutional planning; assessment of the effectiveness of actions resulting from institutional planning.

- Professionalizing institutional management, in order to establish an effective and efficient management system, while avoiding the risk of managerialism, or ignoring academic priorities.

- Recognizing quality as the responsibility of all institutional stakeholders; this requires their involvement in the quality improvement processes, a systematic evaluation of their work and the recognition of their contribution in the different instances of academic or professional development.

\section{V.3. Quality assurance agencies}

Agencies and other quality assurance organizations are responsible for the administration of assessment and accreditation processes. Evidence shows that higher education institutions are quite responsive to the criteria and procedures applied by the agencies. This means that quality assurance processes can either promote a culture of quality and self-assessment, or a culture of compliance, where the focus is on meeting prescriptive requirements; agencies can encourage institutions to develop their own assessment and improvement processes, or they can promote the formal compliance with demands not necessarily associated to the improvement of quality.

- It is therefore important to have in place mechanisms for the cyclic review of standards and procedures with the participation of representatives from higher education institutions and other relevant stakeholders. This would allow for a substantive discussion of quality criteria; it would also help to avoid the excessive formalization and bureaucratization of evaluation processes. Participation in the design and revision of norms, criteria and procedures generates ownership and increases their acceptance and legitimacy, as well as correcting unanticipated effects.

- As has been mentioned before, a key element in this revision is the consideration of the diversity of institutions, programmes, teaching modes, student needs and requirements. Many quality assurance systems use indicators that respond to a traditional university model, 
which is not necessarily aligned with the purposes and characteristics of the institutions they accredit. To recognize the validity of institutions that educate and train for different lives and careers should be a central feature of effective quality assurance mechanisms.

- One of the significant contributions of quality assurance has been to highlight the central role of the teaching function in higher education. It is interesting to note that while everybody recognizes the importance of students in higher education, teaching has a definitely lower status than research, even in institutions whose main task is providing professional degrees. At the same time, quality assurance has failed to emphasize the more substantive aspects of teaching and learning, as it tends to focus on its formal and procedural aspects.

- Finally, it is necessary to emphasize the increased professionalization of quality assurance, and the need to apply the standards or guidelines of good practice that quality assurance networks have systematized. This requires discussing and analysing these guidelines, organize regular training processes and using them as the basis for selfassessment and external review of the agency. Examples of these materials can be found in the European Standards and Guidelines or $\mathrm{ESG}^{16}$ and the Guidelines of Good Practice, GGP. ${ }^{17}$

\section{Final comments}

Progress towards useful and relevant quality assurance processes requires constant review and monitoring of the characteristics of the social and educational systems where these processes operate. Quality assurance should not be an end in itself (although it is becoming this in many countries), but rather a means for the continuing improvement of higher education. Therefore, it must take into consideration the higher education environment, its changes, its emerging features, and, last but not least, the impact quality assurance can have over higher education institutions.

As most guidelines and standards of good practice never tire of repeating, quality is the main responsibility of higher education institutions themselves.

${ }^{16}$ ENQA, "Standards and guidelines for quality assurance in the european higher education area," 2015, http://www.enqa.eu/index.php/home/esg/.

17 INQAAHE, "Guidelines of Good Practice for Quality Assurance," http://www. inqaahe.org/admin/files/assets/subsites/1/documenten/1231430767_inqaahe---guidelines-ofgood-practice[1].pdf, 2006. 
Quality assurance processes make expectations clear, define deadlines, make urgent what is important, but their main function should be to get higher education institutions to take the quality challenge seriously in their governance and management practices.

Finally, it is obvious that higher education is an essentially dynamic social system. It cannot improve as a result of quality assurance processes that are unable to learn about new ways to perform, and what is even more difficult, to un-learn.

\section{Bibliography}

ARCU-SUL. "Sistema ARCU-SUR - Mercosur. s.f." Last accessed August 2017. http://edu .mercosur.int/arcusur/index.php/es/descripcion/127-sistema-arcu-sur-es.

Atria, Raúl. Tendencias en la Educación Superior. El contexto del Aseguramiento e la calidad. Santiago de Chile: Centro Interuniversitario de Desarrollo (CINDA) \& Ril Editores, 2010.

Brunner, Jose Joaquin, and Daniel Miranda. Educación Superior en Iberoamérica. Santiago: CINDA, 2016.

Brunner, José Joaquín, and Rocío Ferrada. Educación Superior en Iberoamérica. Informe 2011. Centro Interuniversitario de Desarrollo CINDA - Universia, Santiago: RIL Editores, 2011.

CINDA. Educación Superior en Iberoamérica. Santiago: CINDA, 2007.

ENQA. "Standards and guidelines for quality assurance in the european higher education area." 2015. http://www.enqa.eu/index.php/home/esg/.

INQAAHE. "Guidelines of Good Practice for Quality Assurance." 2006. http:// www.inqaahe.org/admin/files/assets/subsites/1/documenten/1231430767_ inqaahe---guidelines-of-good-practice[1].pdf.

Lemaitre, Maria Jose, and Elisa Zenteno. Aseguramiento de la calidad en Iberoamérica. Informe Educación Superior 2012. Santiago: CINDA, 2012.

Lemaitre, Maria Jose, and Francisco Durán. Hacia una nueva arquitectura del sistema de educación superior: el régimen de lo público. Santiago: Universidad San Sebastián, 2013.

QAA and British Council. Cultures of Quality: an International Perspective. Gloucester: The Quality Assurance Agency for Higher Education, 2015.

Terkla, Dawn. Institutional Research: What's it all about? PPT presentation to the Algerian Ministry of Education, Tufts University, 2008.

Torre, Daniela, and Gonzalo Zapata. "Impacto de procesos de aseguramiento de la calidad sobre las instituciones de educación superior: un estudio en siete países." In Aseguramiento de la Calidad en Iberoamérica, edited by Maria Jose Lemaitre and Elisa Zenteno. Santiago: CINDA, 2016. 
Trow, M. "Diversity in higher education in the United States of America." Paper presented at the CVCP Seminar on Diversity in Higher Education. London, 1415 September, 1995.

UNESCO. Summary report on of the E-Forum on quality assurance in higher education. Paris: UNESCO, 2015.

\section{About the author}

MARÍA JOSÉ LEMAITRE (mjlemaitre@cinda.cl): Sociologist, with graduate studies in education, is currently the Executive Director of CINDA, a network of universities in Latin America and Europe. She is former president of INQAAHE and of RIACES, the Iberoamerican Network for QA and is currently a member of the Advisory Council of the CHEA International Quality Group. María José Lemaitre was in charge of the design and implementation of quality assurance processes in Chile between 1990 and 2007 and has published many articles on the quality and management of higher education. She has served as a consultant on the development of quality assurance, higher education management and policy design and implementation in the field of higher education, for institutions, governments and bi and multilateral organizations in Central and South America, the Caribbean, the Middle East, Africa, East Europe, Central and Southeast Asia. 


\title{
Quality assurance in Latin America: current situation and future challenges
}

\author{
Maria Jose Lemaitre
}

\section{Copyright}

Copyright for this article is retained by the Publisher. It is an Open Access material that is free for download, distribution, and or reuse in any medium only for non-commercial purposes; provided any applicable legislation is respected, the original work is properly cited, and any changes to the original are clearly indicated. 